\title{
Strategic Interaction and Trade
}

\section{Policymaking: Formal Analysis and Simulation}

\author{
William Roberts Clark ${ }^{1}$, Erick Duchesne ${ }^{2}$ and William L. Reed ${ }^{3}$ \\ ${ }^{1}$ University of Michigan, Ann Arbor, ${ }^{2}$ Université Laval, Québec, and ${ }^{3}$ Rice University, Houston
}

\section{INTRODUCTION}

$\mathfrak{I}$ $\mathrm{T}$ has become increasingly common to recognise that the strategic nature of many topics of interest to students of international relations poses problems for valid inference from observable data. A strategic decision is one in which actors anticipate the likely responses of others, before deciding which course of actions to take over a typically discrete number of possible actions. As such, they attempt to avoid undesirable responses by other actors. Whenever an actor decides on a course of action rather than another, 'she prevents us from observing what would have happened had she chosen the unrealized alternative' (Smith, 1999, pp. 1255-56). Consequently, observed reality is a non-random sample of the possibilities considered by the decision-maker. Smith (1999) and Signorino (1999) use a Monte Carlo quasi-experimental design to clearly demonstrate the inferential errors that are likely to occur when analysts do not handle the strategic process that generated their data carefully. Reed (2000) extends this work with an emphasis on the non-monotonicity of strategic processes. In this study, we follow along the same path by introducing a simple formal model and a short simulation to demonstrate that selection biases may have an impact on potential analyses of trade policy decisions.

States use a variety of trade instruments in an attempt to change the behaviour of the target state. Accordingly, decision-makers set off a course of action with an eye toward how the targeted state will respond. Consequently, trade policymaking is an intrinsically strategic decision. Nevertheless, most of what we know about the use and effectiveness of trade policies comes from studies that pay little attention to the selection effects imposed by strategic choice. Empirical studies that evaluate the initiation and outcome of Section (Super) 301 (McMillan, 1990; Bayard and Elliott, 1994; and Duchesne, 1997) or GATT/WTO disputes (Busch 
and Reinhardt, 2001 and 2002) provide us with a better understanding of the factors that lead to a successful resolution of trade conflicts, but they also fail to account for selection effects. ${ }^{1}$

It is only recently that the impact of selection effects has been identified and studied in the subfield of international political economy (Noland, 1997; Busch, 2000; Przeworski and Vreeland, 2000; Reinhardt, 2001; and Nooruddin, 2002). Noland (1997) and Busch (2000) correctly assert that there are several steps preceding an American decision to target a foreign entity for trade retaliation. Noland (1997) studies the United States unilateral imposition of trade retaliation via Section 301 of the 1974 Trade Act, while Busch (2000) focuses on the multilateral dispute settlement settings of the General Agreement on Tariffs and Trade (GATT). They both delve into the machinery of American trade policy and make an important distinction between the 'opening' of a case and its 'outcome'. However elegant their statistical analyses, they come short of accounting formally or empirically for selections biases. In contrast, Przeworski and Vreeland (2000) and Nooruddin (2002) are representative of few statistical studies that account directly for selections biases in the subfield of international political economy. The former cast their lot in the study of the International Monetary Fund's (IMF) loan-granting process, while the latter explores the United States' decision to impose sanctions on foreign targets. This limited number of studies taking seriously the potential impact of non-random selections biases provides us with the motivation to take a deeper look at this important issue in the subfield of international political economy.

\section{GAME-THEORETICAL MODEL}

As a heuristic device, we analyse the US decision to use Section (Super) 301 to demonstrate the potential pitfalls associated with the omission of selections biases in statistical studies. This trade policy-making tool constitutes a prime example of the strategic use of economic sanctions. This important component of US trade laws represents an assertive position by American lawmakers, coined aggressive unilateralism by Bhagwati (Bhagwati and Patrick, 1990), which demands that its trading partners reduce their real or imaginary barriers to US exports and investments. The United States decides what are deemed unfair practices and asks for trade concessions without offering any concessions. Section (Super) 301 is often publicised and backed by implicit and, often, explicit threats

\footnotetext{
${ }^{1}$ A study by Reinhardt (2001) on the adjudication of GATT disputes constitutes a clear breakthrough in the study of counterfactuals in International Political Economy. His article develops an incomplete information model of trade disputes under GATT that reveals 'not only the general patterns of concessions before and after the rulings but also the variation in the outcomes across rulings of different types' (p. 190).
} 
of retaliation. Hence, Section (Super) 301 does not constitute an episode of sanctions per se. Target countries are allowed to negotiate an agreement before America puts forth sanctions vis-à-vis these states. In other words, a country is targeted for its unfair trade practices, but it has another chance to mend its fences with its American counterparts before sanctions are implemented. More specifically, the Trade Act of 1974, under Sections 301-302:2

granted the President authority to take any of a broad range of actions against a country that maintains unjustifiable or unreasonable tariff or other import restrictions (Destler, 1995, p. 126).

It also authorised action against foreign export subsidies. The Trade Agreement Act of 1979 expanded the Trade Act of 1974 and gave to the President the authority to enforce trade agreements. It also allowed for detailed procedures for investigation (including deadlines for action), and the use of available settlement procedures (Bayard and Elliott, 1994). Later, the Trade and Tariff Act of 1984 authorised retaliation in the service sector (idem). Finally, 'the Omnibus Trade and Competitiveness Act of 1988 created Super 301' and shifted the authority to retaliate from the President to the United States Trade Representative (USTR). However, the process is still dependent on some presidential directives (idem). It also made retaliation against 'unjustifiable' practices mandatory. ${ }^{3}$

In this section, we suggest a game-theoretical model that accounts for the strategic nature of the decision-making process of opening a Section (Super) 301 case (see Figure 1).

The interplay between domestic lobbying groups $(L)$, the USTR $(G)$ and foreign targets $(T)$ can be represented in a simple extensive form game, in which a lobbying group moves first and decides whether to file a petition with the government claiming injury from unfair trading practices by a foreign government. If a petition is filed, the President and, later, the USTR decide whether to open a case against the foreign target. If the US opens a case, the foreign target then decides whether to stand firm in the face of this threat or to back down and change its policy. Finally, if the foreign government stands firm, the President/USTR decides whether to make good on its threat and enact sanctions or to back down. ${ }^{4}$

\footnotetext{
${ }^{2}$ It is not our intention here to provide a detailed assessment of the evolution of Section (Super) 301. For more information see Bhagwati and Patrick (1990) and Bayard and Elliot (1994), especially Chapter 2 .

${ }^{3}$ This evolution of American trade laws can have an impact on bargaining outcomes. For instance, in the escalation game that we introduce below, the last branch of the tree becomes irrelevant if American retaliation becomes mandatory.

${ }^{4}$ We could add two additional moves in the game by the target country/firm. In a first move, the target could have to make a decision on whether or not to initiate a trade policy that can potentially prod an American firm to file a petition with the USTR. We could also add a move by a target after a petition was filed. A target could decide to back down (i.e. change its trade policy to American satisfaction) before a formal case is open. The omission of these two moves inserts additional selection biases. We have decided to present a simpler game at this juncture of our research.
} 
FIGURE 1

Extensive Form of Bargaining Game

\section{Outcomes}

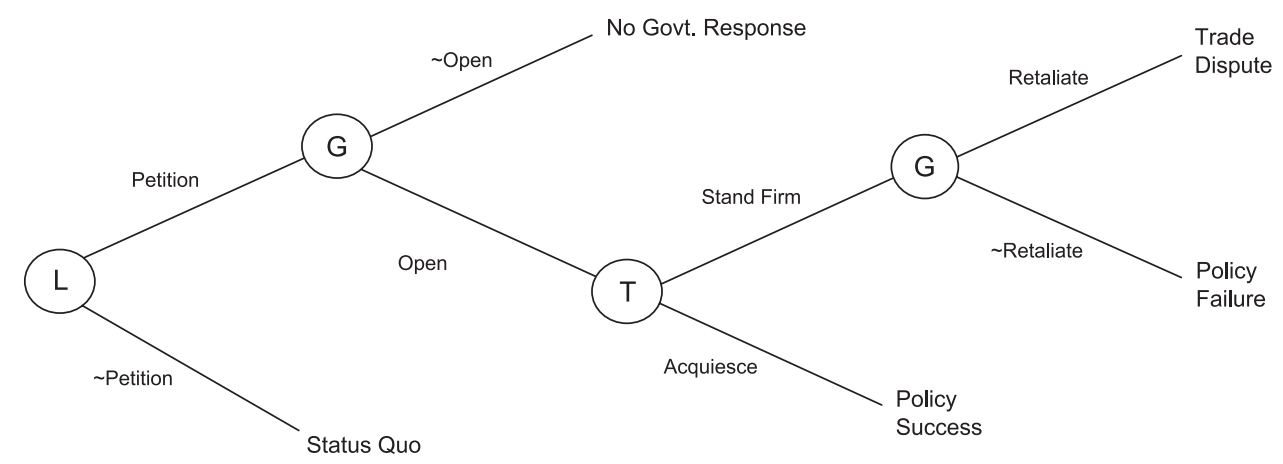

\section{a. Outcomes/Pay-offs}

If the lobbying group does not petition, each player receives its status quo payoff $s q_{i}$. If the lobbying group files and the President/USTR does not open a case the lobbying group receives its status quo pay-off less the cost of lobbying, $-c_{L}$, and the President/USTR and the foreign state receive their status quo pay-off. ${ }^{5}$ If the President/USTR opens a case and the foreign target backs down, the firm receives increased access to the foreign market and pays the cost of filing $\left(a_{L}-\right.$ $\left.c_{L}\right)$, the government receives some benefit from increased access $\left(a_{G}\right)$ and the target government loses the benefit it derived from generating rents for its protected industry $\left(-r_{T}\right)$. If, however, the target state stands firm in the face of the President/ USTR's threats and the President/USTR back down, the firm receives its status quo pay-off less the costs of lobbying $\left(-c_{L}\right)$, the government pays a cost for issuing a threat and backing down $\left(-c_{G}\right)$ and the foreign state receives its status quo pay-off $\left(s q_{T}\right)$. Finally, if the President/USTR makes good on its threat to sanction the target state, a trade dispute takes place. We represent the actors' evaluations of such a dispute as lotteries. There is some probability $p$ that the dispute will end with the target state granting access to its market, and some probability $(1-p)$ that the dispute will end with the US removing sanctions. The actors' pay-offs, therefore, can be seen as weighted averages of what they received when, on the one hand, the target backed down $\left(a_{L}-c_{L}, a_{G},-r_{T}\right)$ and when the US backed down $\left(-c_{L},-c_{G}, s q_{T}\right)$. However, it is important to recognise that there are other consequences from an ongoing trade dispute. First, there is likely

\footnotetext{
${ }^{5}$ One can imagine a 'domestic politics' sub-game occurring after the US fails to issue a threat in which the lobbying group decides whether or not to punish the President/USTR in some way for its lack of responsiveness, but since our model is not primarily concerned with that particular domestic politics story, we will not pursue this here.
} 
to be a disruption to markets that impose an efficiency cost on all actors involved $\left(-d_{i}\right)$. Second, this disruption creates an opportunity for rent-seeking by firms in the US from which policy-makers may also derive benefits (either in the form of enhanced political support or revenues) $r_{i}, I \in(L, G)$. Finally, the imposition of sanctions reduces the target country's access to US markets $\left(-a_{T}\right){ }^{6}$ Thus, the firm's pay-off for a trade dispute is:

$$
p\left(a_{L}-c_{L}\right)+(1-p)\left(-c_{L}\right)+r_{L}-d_{L}
$$

This simplifies to:

$$
p a_{L}-c_{L}+r_{L}-d_{L}
$$

The USTR's pay-off for a trade dispute is:

$$
p a_{G}+(1-p)\left(-c_{G}\right)+r_{G}-d_{G} .
$$

The target state's pay-off for a trade dispute is given by:

$$
p\left(-r_{T}\right)+(1-p) s q-a_{T}-d_{T} .
$$

We will assume that all costs are non-zero $\left(c_{i}>0, d_{i}>0\right)$ and that each actor places a positive value on access to the other's market $a_{i}>0$ and appropriating rents $r_{i}>0$. Without loss of generality, pay-offs can fruitfully be normalised in the following manner. Assume that at the start of the game the target state has privileged access to one of its markets and it assigns a value of one to this outcome. The firm and the USTR, under such conditions, receive a pay-off of zero. Should the US gain access, the lobbying group and the USTR each receive a pay-off of one. Figure 2 displays the extensive form of the game after pay-offs have been normalised and, where possible, the pay-offs simplified.

\section{b. Behaviour Under Complete Information}

The complete information game can be solved using backward induction.

(i) Trade disputes

The government responds to a target that stands firm by adopting retaliatory measures when:

$$
p+(1-p)\left(-c_{G}\right)+r_{G}-d_{G} \geq-c_{G},
$$

\footnotetext{
${ }^{6}$ The magnitude of the consequences of the trade dispute is determined, in part, by the duration and intensity of the dispute. The duration of the negotiations and magnitude of a trade dispute can be explained by a Stahl-Rubinstein bargaining model (Duchesne, 1997, Ch. 3).
} 
FIGURE 2

The Extensive Form of the Steps to a Trade Dispute, with Normalised Pay-offs

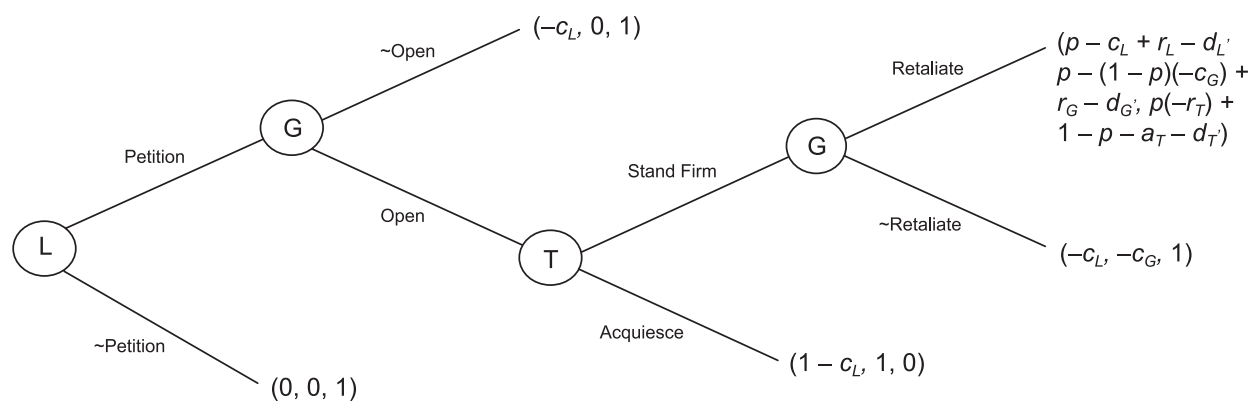

which is the case whenever $p\left(1+c_{G}\right)+r_{G}-d_{G} \geq 0$. Not surprisingly, the likelihood of a trade dispute occurring is increasing with the government's confidence that it will accomplish its goal through such a dispute. Put differently, the state will only retaliate when it is sufficiently confident that it will win a trade dispute, or (solving (1) for $p$ ) when:

$$
p \geq \frac{d_{G}-r_{G}}{1+c_{G}} .
$$

This can be interpreted as the condition that must be satisfied for the government's decision to open a case to be considered a credible threat. Note that when the right-hand side of (2) is greater than one, no amount of confidence in the outcome of a trade dispute can make retaliatory threats credible. This is most likely to be the case when trade disputes create large disruptions in markets compared to the rents they generate for the threatening state and the cost of policy failure (i.e. when $d_{G}-r_{G}-c_{G}>1$ ). Notice that when the right-hand side of the equation is greater than one and a case is not open, this case is not included in previous statistical analyses (Bayard and Elliott, 1994; and Duchesne, 1997). Consequently, it introduces a selection bias that may inflate the level of bargaining success for American negotiators.

The target state's behaviour will, of course, hinge on whether the credibility condition in (2) is met. When (2) is met, the target state chooses, in essence, between acquiescing and engaging in a trade dispute by standing firm against a resolute government. It will stand firm if:

$$
1 \geq p_{T}+a_{T}+d_{T}
$$

but will acquiesce otherwise. One can think of the case where (3) is satisfied as the case of the 'resolute target'. Note that the target's resolve is decreasing as its probability of 'losing' a trade dispute is increasing, the utility it derives from the access to the US market, and the disruptions expected from a dispute. 
Trade disputes occur only when (2) and (3) are both met; that is, when a resolute target encounters a credible threat. Put differently, $p$ has to be sufficiently large for the government to be confident that it can win a dispute, but not so large that the target state will do better by acquiescing. ${ }^{7}$

\section{(ii) Opening a case}

Clearly, the decision by the government to open a case is influenced by its expectations regarding the target's response and its chances of prevailing should a full-scale trade dispute erupt. For example, if (2) and (3) are satisfied, the government chooses between opening a case that will escalate and averting a trade dispute by rebuffing the lobbying group. It will choose the former only when the left-hand side of (1) yields a higher pay-off than the status quo, which is the case only if:

$$
p+(1-p)\left(-c_{G}\right)+r_{G}-d_{G} \geq 0 .
$$

This is true if and only if:

$$
p \geq \frac{c_{G}+d_{G}-r_{G}}{1+c_{G}}
$$

When (2) is not satisfied, then the target state always responds to the opening of a case by standing firm and since the government always does better by not opening a case that it knows it will abandon, it will not initiate a case under such circumstances. Note, this last result means that policy failure that is not preceded by retaliatory measures should not occur under complete information. In contrast, policy success without the resort to retaliatory measures can be observed under complete information. This is so because if (3) is not satisfied, then the government will be willing to open a case whether or not it is willing to make good on its threat to adopt retaliatory measures, because the target acquiescence means policy success in either case.

Table 1 summarises the various outcomes that can be observed in equilibrium in the complete information game. Notice that each of the conditions on equilibrium behaviour can be expressed in terms of the probability that the US will prevail in a trade dispute, should one occur. Such a conflict could, itself, be modelled as a bargaining situation in which disputants negotiate over how to divide the potential gains from trade while costly delays result in the erosion of the overall size of the pie. Following Schelling (1960) and Putnam (1988),

${ }^{7}$ More formally, the following is a necessary condition for a trade dispute under complete information:

$$
1-a_{T}-d_{T} \geq p \geq \frac{d_{G}-r_{G}}{1-c_{G}} .
$$


TABLE 1

Equilibrium Outcomes Under Various Conditions

\begin{tabular}{|c|c|c|c|c|}
\hline \multirow{3}{*}{$\begin{array}{l} \\
\\
\text { Inequality } \\
\text { (Condition (3)) } \\
\text { 'Resolute Target' }\end{array}$} & & & \multicolumn{2}{|c|}{$\begin{array}{l}\text { Inequality (Condition (2)) } \\
\text { 'Credible Threat' } \\
p \geq \frac{d_{G}-r_{G}}{1+c_{G}}\end{array}$} \\
\hline & $1-a_{T}-d_{T} \geq p$ & $\begin{array}{l}\text { Not } \\
\text { Satisfied }\end{array}$ & Policy Success & No Case \\
\hline & & Satisfied & $\begin{array}{l}\text { Trade Dispute } \\
\text { or } \\
\text { No Case* }\end{array}$ & No Case \\
\hline
\end{tabular}

* If $p \geq \frac{c_{G}+d_{G}-r_{G}}{1+c_{G}}$ then a trade dispute occurs; if $p \leq \frac{c_{G}+d_{G}-r_{G}}{1+c_{G}}$ then no case occurs (condition (5)).

Duchesne and Clark (1995), and Clark, Duchesne and Meunier (2000) argue that success in such a bargaining situation is increasing in the number of domestic veto players a country possesses, relative to the number of veto players in the country with which it is bargaining. Thus, as the ratio between the number of veto players in the US to the number of veto players in the target country rises, the probability of US success in a trade dispute $(p)$ rises. In light of this interpretation of $p$, therefore, Table 1 suggests that when the 'institutional advantage' of the US over its trading partners is low, the conditions for a credible American threat are less likely to be met, and consequently no cases will be opened.

President/USTR will tend to not open cases. When the 'institutional' advantage is large enough to satisfy the credibility constraint and large enough to deter resistance from targets, the USTR/President will open cases and the target country will adjust its policies to deter a dispute. ${ }^{8}$ In a middle range, however, the probability of US success in a dispute may be sufficiently high so as to be credible, but sufficiently low that the target state prefers entering a dispute to backing down. ${ }^{9}$

These conditions are very different from Duchesne's (1997) theoretical and empirical model. If we interpreted his model correctly, he assumed that a larger $p$ - that is, when the structure of negotiation favours the Americans - leads to an

\footnotetext{
${ }^{8}$ In fact, one can imagine a model in which the target country's policy is endogenous and accommodative policies are adopted in order to deter filings from the US.

${ }^{9}$ Note that the potential for rent-seeking behaviour created by trade disputes leaves open the possibility that both states will enter a dispute even when there is complete information. In contrast, many crisis bargaining models treat war as an outcome that players associate with negative expected utility. As a result, wars in these models only occur when information is limited.
} 
outcome where the Americans are more likely to reach their objectives. Conditions (2), (3) and (5) demonstrate that it may not be the case. These conditions assume a non-monotonic relationship between the probability of success and the decision to open a Section 301 case. There are a few reasons for his model misspecification. First, by omitting to test for non-random selection of cases, his empirical analysis only includes cases where condition (2) is met. As our analysis demonstrates, the cases that fall in the left-side column of Table 1 have an impact on the outcome of a trade negotiation. Second, even if condition (2) is met, there is no guarantee that it will increase the likelihood of American bargaining success, which Duchesne's non-strategic empirical model assumes. They may reach their objectives when they face an irresolute target (condition (3) is not met). If this is the case, there is no discrepancy between the ordered multinomial logit analysis and the strategic choice model. If they face a resolute target (condition (3) is met), the outcome is indeterminate. It is possible that a case will not be opened if condition (5) is not met or the case will escalate to trade war. If the case escalates to a trade war, Americans face the probability $(1-p)$ that they will not meet their objectives (policy failure). If indeed it leads to a policy failure, then there is an important discrepancy between the two models. Third, notice the difference between the expectations of the ordered multinomial logit analysis and our strategic game-theoretical model in regards to the probability of policy failure. The multinomial logit analysis expectation is that as the structure of negotiation shifts in favour of a foreign target, the probability of American policy failure increases. In the strategic model, policy failure occurs only under strict conditions. It can only happen when conditions (2), (3) and (5) are met, that is when both sides are willing to take the risk of ending up in a trade war. It can only happen in the middle range cases where both sides believe that their advantageous structure of negotiation is well worth the risk of a trade dispute. Unfortunately, many of the cases that we observe fall in this lower left cell of Table 1. Therefore, assuming a linear relationship between variables, when the true relationship is non-monotonic, leads to an estimation that is biased and inconsistent.

\section{(iii) Petitioning for the opening of a case}

Since lobbying is costly, it will only take place when there is some expectation that the government will be responsive. Thus, private sector groups will lobby the government only if there is some chance that the government will open a case that has a significant chance of being successful. Thus, if the credibility condition (2) is not satisfied, the lobbying group faces a choice between not lobbying for policy changes or lobbying for policy changes and getting no response. Because lobbying is costly and instrumental, we do not observe a demand for policy change. If the credibility condition is satisfied, and the institutional advantage of the US is sufficiently large to deter resistance from the target (i.e. (3) is not satisfied) then the lobbying group will lobby as long as the cost of doing so is not 
greater than the benefits of opening up foreign markets. ${ }^{10}$ If the probability of US success is sufficiently high to make retaliatory threats attractive and credible, but not so high as to lead to target acquiescence, then interest groups will lobby for them if $p-c_{L}+r_{L}-d_{L}>0$.

The decision by a lobbying group to maintain the status quo introduces a selection effect at the beginning of the game. It can be in the anticipation that the issue would not be resolved to the American satisfaction that the firm decides to maintain the status quo. Under this scenario, the firm might prefer to maintain the status quo, even if it means that it will still face an 'unfair' trade practice by a foreign target, and avoid paying the cost of lobbying. This indicates that there is connection between the decision to initiate a case and the outcome of a trade negotiation. If a case is not initiated, we do not know what the decisions by other actors would have been at subsequent nodes. There is a strong possibility that if such cases had been initiated, it would decrease the rate of success obtained by American negotiators. Ergo, the factors (e.g. resolve and willingness) that affect the decision to initiate a case can also be factors that affect the outcome of an eventual negotiation. Empirically, it signifies that unobserved factors such as resolve and willingness are relegated to the error terms in both equations. Consequently, the error terms in both equations are correlated and an ordered multinomial logit analysis does not mirror the theoretical and empirical relationship between case initiation and negotiation outcome.

\section{SIMULATIONS}

Our formalisation suggests that the choice to open a Section 301 case is strategic. The decision to open the case is explicitly based on future expectations about the likelihood of a trade dispute. As a result, observations of the use of Section 301 are not a random sample of cases. Rather, the use of Section 301 represents a self-selected set of cases based on the characteristics of the cases themselves. Therefore, empirical analyses of Section 301 failing to account for factors influencing the government's strategic choice to open a case may lead to fallacious conclusions. Specifically, our formalisation suggests some of the same factors influencing the decision to open a Section 301 case are also related to the subsequent evolution of the case. This is a classic example of selection bias induced by strategic interaction. We use Monte Carlo simulations to illustrate how the strategic choice to open a Section 301 case may cause selection bias. Monte Carlo simulations are a useful tool for studying the effect of econometric modelling choices and characteristics of historical data on our ability to consistently

${ }^{10}$ Obviously, since there is only one lobbying group in our model, this abstracts from the free-rider problem. 
estimate the population parameters of interest in a controlled environment. We use the simulations to gather information about the sampling distribution of our estimate of institutional constraints. This allows us to compare the sampling distribution under different conditions to the population parameter for institutional constraints.

It is important to consider how non-random selection may affect studies of Section 301, because our model shows that the likelihood of the government opening a case is a function of the government's bargaining power. In turn, the government's bargaining power is also related to the decision to retaliate against a target with a trade dispute. Put simply, the bargaining power of the government has both a direct and indirect effect on the probability of a trade dispute. The direct effect appears in the government's decision to retaliate against the target state, and the indirect effect comes through the government's decision to open the case in the first place. Empirical studies only analysing the government's decision to initiate a trade dispute miss the indirect effect of the government's bargaining power through the government's choice to open the case in the first place.

We begin by assuming the government's bargaining power is increasing with its institutional constraints. Therefore, we expect high institutional constraints to be related to the decision to open a Section 301 case. We randomly generate 1,000 observations of a constraint variable normally distributed with a mean of zero and a variance of one. Next, we create a variable indexing the state's decision to open a Section 301 case:

$$
\text { Open }=\alpha_{0}+\alpha_{1} \text { Constraints }+\varepsilon,
$$

where Open represents the latent utility for opening a Section 301 case and Constraints enhance the utility for opening such a case. Moreover, $\varepsilon$ is a random error term normally distributed with a mean of zero and a variance of one. Next, we generate a variable indexing the decision to initiate a trade dispute:

$$
\text { Trade Dispute }=\beta_{0}+\beta_{1} \text { Constraints }+u \text {, }
$$

where Trade Dispute is the latent utility for initiating a trade dispute as a function of institutional constraints and random error term $u$ distributed normally with a mean of zero and variance equal to one. In addition, the correlation between $\varepsilon$ and $u$ is indexed by $\rho$.

We normalise the intercepts in the models to zero and we set $\alpha_{1}=6$ and $\beta_{1}=4$. These are the true population parameters. The purpose of the simulation is to determine how the strategic choice to open a case may limit our ability to recover a consistent estimate of the population parameters. That is, how does the mean of the sampling distribution for our estimate of $\beta_{1}$ compare to the population 
TABLE 2

Results of Monte Carlo Simulation

\begin{tabular}{lllll}
\hline$\rho$ & Estimate & Simulations & Mean & Standard Deviation \\
\hline-0.9 & $\beta$ & 1,000 & 4.245962 & 0.069365 \\
-0.9 & se & 1,000 & 0.071237 & 0.003895 \\
-0.7 & $\beta$ & 1,000 & 4.191348 & 0.07358 \\
-0.7 & se & 1,000 & 0.071803 & 0.003731 \\
-0.5 & $\beta$ & 1,000 & 4.137475 & 0.070382 \\
-0.5 & se & 1,000 & 0.072397 & 0.003733 \\
-0.3 & $\beta$ & 1,000 & 4.078965 & 0.073301 \\
-0.3 & se & 1,000 & 0.072551 & 0.003698 \\
0 & $\beta$ & 1,000 & 3.998182 & 0.073513 \\
0 & se & 1,000 & 0.072845 & 0.00378 \\
0.3 & $\beta$ & 1,000 & 3.916713 & 0.07296 \\
0.3 & se & 1,000 & 0.072644 & 0.003721 \\
0.5 & $\beta$ & 1,000 & 3.859921 & 0.074796 \\
0.5 & se & 1,000 & 0.07224 & 0.003706 \\
0.7 & $\beta$ & 1,000 & 3.80811 & 0.073176 \\
0.7 & se & 1,000 & 0.071858 & 0.00372 \\
0.9 & $\beta$ & 1,000 & 3.753627 & 0.072165 \\
0.9 & se & 1,000 & 0.071466 & 0.003654 \\
\hline
\end{tabular}

parameter. To illustrate the self-selection anticipated by our formal model, we only analyse the case where Open $>0$. All other cases are dropped. This captures the self-selection into trade disputes as a function of institutional constraints. Essentially, we assume cases are only opened when the latent utility for opening the dispute is greater than zero. If the latent utility for opening the case is less than zero, no case is opened, making it impossible to observe a trade dispute. Cases are only opened when the government expects to benefit. We repeat this simulation 1,000 times for values of $\rho$ from -0.9 to 0.9 . Each set of 1,000 simulations makes up the sampling distribution for our estimate of $\beta_{1}$ at various levels of $\rho$.

Table 2 summarises the difference between the true effect of institutional constraints on the likelihood of a trade dispute and the relationship in the selfselected sample as a function of the correlation between the disturbance terms in both models. The first column indexes the correlation between the error terms in the model of opening a Section 301 case and the decision to initiate a trade dispute. The last two columns show the mean and standard deviation of the sampling distribution for the estimated parameter. Only when there is no correlation between the error terms do we recover the correct effect of institutional constraints on the likelihood of a trade dispute. Moreover, the inconsistency increases with $\rho$ and can go either way depending on the sign on $\rho$. As $\rho$ goes to its negative extreme, the estimated effect of institutional constraints is inflated. Likewise, the estimated effect of institutional constraints is underestimated as $\rho$ 
goes to its positive extreme. Depending on the correlation between the error terms, the inconsistency can be substantial. The results suggest it is important to consider the decision to initiate a trade dispute and the decision to open a Section 301 case jointly, and studies failing to correct for the effect of the strategic choice to open a Section 301 case may yield misleading results about the decision to initiate a trade dispute. An important next step for this research is to construct an econometric model equipped to jointly model the decision to open a Section 301 case and the decision to initiate a trade dispute.

\section{CONCLUSION}

This article has identified some potential estimation problems in the subfield of international political economy. Our game-theoretical model and Monte Carlo simulation demonstrated that, despite significant results, some statistical studies of trade policy-making might potentially suffer from misspecification due to non-random selection effects. These problems are not inherent to the assessment of the level of success by American negotiators when they choose to formally open a Section 301 case. For instance, our model could also shed light on the decision to open anti-dumping and countervailing cases, as well as the decision to use economic sanctions against a rogue state. In addition, it is not the exclusive prerogative of the United States to use such policy instruments and accordingly further studies should move into the comparative realm by assessing the impact of strategic interaction on trade policy decisions of a vast number of states.

In this article we chose to focus on Section 301 because it constitutes a policy tool that has been intensely studied from different angles by jurists, political scientists and economists. Despite such an enormous literature on the effectiveness of this policy tool, we can raise some doubts on the many of the conclusions reached in these studies. The decision to use Section 301 as a heuristic device was a conscious decision by the authors. If we can be potentially wrong about something we think we know a lot about, it is also likely that we reach erroneous conclusions about things we know little about.

\section{REFERENCES}

Bayard, T. O. and K. A. Elliott (1994), Reciprocity and Retaliation in US Trade Policy (Washington, DC: Institute for International Economics).

Bhagwati, J. and H. Patrick (eds.) (1990), Aggressive Unilateralism: America's 301 Trade Policy and the World Trading System (Ann Arbor, MI: University of Michigan Press).

Busch, M. L. (2000), 'Democracy, Consultation, and the Paneling of Disputes under GATT', Journal of Conflict Resolution, 44, 4, 425-46.

Busch, M. L. and E. Reinhardt (2001), 'Bargaining in the Shadow of the Law: Early Settlement in GATT/WTO Disputes', Fordham International Law Journal, 24, 1-2, 158-72. 
Busch, M. L. and E. Reinhardt (2002), 'Testing International Trade Law: Empirical Studies of GATT/WTO Dispute Settlement', in D. L. M. Kennedy and J. D. Southwick (eds.), The Political Economy of International Trade Law: Essays in Honor of Robert E. Hudec (New York: Cambridge University Press), 457-81.

Clark, W. R., E. Duchesne and S. Meunier (2000), 'Domestic and International Symmetries in the United States-European Union Trade Negotiations', International Negotiation, 5, 1, 69-95.

Destler, I. M. (1995), American Trade Politics (3rd edn., Washington, DC: Institute for International Economics).

Duchesne, E. (1997), 'International Bilateral Trade and Investment Negotiations: Theory, Formal Model, and Empirical Evidences', Ph.D. Dissertation (Michigan State University).

Duchesne, E. and W. R. Clark (1995), 'A Formal Model of the Canada-US Free Trade Agreement', Prepared for presentation at the annual conference of the Canadian Political Science Association (June).

McMillan, J. (1990), 'Strategic Bargaining and Section 301', in J. Bhagwati and H. T. Patrick (eds.), Aggressive Unilateralism: America's 301 Trade Strategy and the World Trading System (Ann Arbor, MI: University of Michigan Press), 203-16.

Noland, M. (1997), 'Chasing Phantoms: The Political Economy of USTR', International Organization, 51, 3, 365-87.

Nooruddin, I. (2002), 'Modeling Selection Bias in Studies of Sanctions Efficacy', International Interaction, 28, 1, 57-74.

Przeworski, A. and J. R. Vreeland (2000), 'The Effect of IMF Programs on Economic Growth', Journal of Development Economics, 62, 2, 385-421.

Putnam, R. D. (1988), 'Diplomacy and Domestic Politics: The Logic of Two-level Games', International Organization, 42, 3, 427-60.

Reed, W. (2000), 'A Unified Statistical Model of Conflict Onset and Escalation', American Journal of Political Science, 44, 1, 84-93.

Reinhardt, E. (2001), 'Adjudication Without Enforcement in GATT Disputes', Journal of Conflict Resolution, 45, 2, 174-95.

Schelling, T. (1960), The Strategy of Conflict (Cambridge, MA: Harvard University Press).

Signorino, C. S. (1999), 'Strategic Interaction and the Statistical Analysis of International Conflict', American Political Science Review, 93, 2, 279-98.

Smith, A. (1999), 'Testing Theories of Strategic Choice: The Example of Crisis Escalation', American Journal of Political Science, 43, 4, 1254-83. 